NOTICE: this is the author's version of a work that was accepted for publication in Journal of Environmental Management. Changes resulting from the publishing process, such as peer review, editing, corrections, structural formatting, and other quality control mechanisms may not be reflected in this document. Changes may have been made to this work since it was submitted for publication. A definitive version was subsequently published in JOURNAL OF ENVIRONMENTAL MANAGEMENT, [VOL105, (2012)] DOI:10.1016/.j.jenvman.2012.03.037

Please cite this article as: Chiang, Y.W., Santos, R.M., Ghyselbrecht, K., Cappuyns, V., Martens, J.A., Swennen, R., Van Gerven, T., Meesschaert, B. (2012). Strategic selection of an optimal sorbent mixture for in-situ remediation of heavy metal contaminated sediments: framework and case study. Journal of Environmental Management, 105, 1-11.

\title{
Strategic selection of an optimal sorbent mixture for in-situ remediation of heavy metal contaminated sediments: framework and case study
}

Y.W. Chiang ${ }^{\mathrm{a}, *}$, R.M. Santos ${ }^{\mathrm{b}}$, K. Ghyselbrecht ${ }^{\mathrm{c}}$, V. Cappuyns ${ }^{\mathrm{d}}$, J. A. Martens ${ }^{\mathrm{a}}$, R. Swennen ${ }^{\mathrm{d}}$, T. Van Gerven ${ }^{\mathrm{b}}$, B. Meesschaert ${ }^{\mathrm{a}, \mathrm{c}}$

${ }^{a}$ Department of Microbial and Molecular Systems, Katholieke Universiteit Leuven, 3001 Heverlee, Belgium

${ }^{b}$ Department of Chemical Engineering, Katholieke Universiteit Leuven, 3001 Heverlee, Belgium

${ }^{c}$ Faculty of Industrial Engineering Sciences and Technology, Katholieke Hogeschool BruggeOostende, 8400 Oostende, Belgium

${ }^{\mathrm{d}}$ Department of Earth and Environmental Sciences, Katholieke Universiteit Leuven, 3001 Heverlee, Belgium

*Corresponding author: Department of Microbial and Molecular Systems, Katholieke Universiteit Leuven, Kasteelpark Arenberg 23, 3001 Heverlee, Belgium. Tel./Fax: +32 59569053.

E-mail addresses: yiwai.chiang@biw.kuleuven.be (Y.W. Chiang); boudewijn.meesschaert@biw.kuleuven.be (B. Meesschaert)

\begin{abstract}
:
Aquatic sediments contaminated with heavy metals originating from mining and metallurgical activities of aquatic sediments poses significant risk to the environment and human health due to the fact that these sediments not only act as a sink for heavy metals, but can also constitute a secondary source of heavy metal contamination. A variety of sorbent materials has
\end{abstract}


demonstrated the potential to immobilize heavy metals. However, the complexity of multielement contamination makes choosing the appropriate sorbent mixture and application dosage highly challenging. In this paper, a strategic framework is designed to systematically address the development of an in-situ sediment remediation solution through Assessment, Feasibility and Performance studies. The decision making tools and the experimental procedures needed to identify the optimum sorbent mixtures are detailed. Particular emphasis is given to the utilization and combination of commercially available, and waste-derived sorbents to enhance the sustainability of the solution. A specific case study for a contaminated sediment site in Northern Belgium with high levels of $\mathrm{As}, \mathrm{Cd}, \mathrm{Pb}$ and $\mathrm{Zn}$ originating from metallurgical activities is presented. The proposed framework is utilized to achieve the required remediation targets and to meet the imposed regulations on material application in natural environments.

Keywords: Remediation; Adsorption; Heavy metal; Sediment; Waste-turned-sorbent, In-situ

\section{Introduction}

Mining and metallurgical activities have induced historical soil and groundwater pollution by heavy metals around the world. Geochemical weathering processes acting upon the metallurgical wastes initiate the process of spreading these anthropogenic heavy metal from the contaminated areas into the environment. Hence, the contaminated sites are only the beginning of toxic contaminant release; toxic substances can follow different environmental pathways and accumulate in environmental sinks. Sediments at the bottom of rivers, creeks and brooks are such environmental sinks for toxic substances (Warren, 1981; Basta and McGowen, 2004). The redistribution of heavy metals by means of solute transport mechanisms can adversely affect water resources and endanger the health of surrounding ecosystems and human populations. Cost effective and ecological remediation of these sites is important to enhance the sustainable future of the metals industry.

Remediation refers to the process of environmental cleanup of contaminated sites, and the techniques to decrease or eliminate contamination from soil, sediment, surface water or groundwater (Page, 1997). The complexity of these systems often requires unique treatment solutions, which must result from detailed research and development of appropriate technologies. Literature on sorption processes for an array of heavy metals is abundant, each offering a unique solution and point of view (notable reviews by Shi et al. 2009, Yadanaparthi et al. 2009, and Hashim et al. 2011). However scientific literature customarily focuses on the effect of single adsorbents on heavy metal adsorption. Moreover, the effectiveness of sorbents is most often discussed only with regards to relative performance and the fitting of adsorption isotherms, rarely comparing achieved results to hard targets or regulated values. These shortcomings generate a disconnect between scientific research and industrial practice, making it difficult for novel technologies and innovative engineering approaches to be implemented in the real world. 
The authors of this paper herein set out to establish a systematic approach to the development of optimized remediation solutions. This work aims to provide the strategy needed to tackle heavy metal contamination in sediments, and guidance on bridging the gap between laboratorybased scientific development and real world field application of sorbents. Emphasis is given to in-situ adsorption remediation, which is an attractive method for remediation of large and dispersed contamination sites. Focus on the utilization of both commercially available and wastederived sorbents is given. A strategic framework is detailed, and the efficacy of the proposed framework is illustrated by a case study on the remediation of sediments contaminated by the non-ferrous industry in Northern Belgium.

\section{Remediation Assessment Strategy}

The detailed strategy for assessment of the optimal remediation approach for contaminated sediment treatment by means of sorbent use has been defined by benchmarking common methodologies applied in literature and past experiences garnered by the present authors. In particular, attention is drawn to the challenge of treating multi-element contaminated sites, where single sorbent application is not sufficient to reach the desired remediation results (i.e. meeting environmental regulations of contaminant release), and thus a sorbent mixture is required. The principal aims of this strategy, illustrated by the framework in Fig. 1, are outlined as:

- Identification and quantification of contaminants;

- Assessment of suitability for the application of in-situ remediation method;

- Selection of potential sorbents;

- Characterization of individual sorbent performance towards the targeted contaminants;

- Determination of individual sorbent performance on sediment treatment;

- Selection of most effective sorbents, and estimation of optimal sorbent mixture composition and application dosage based on the Decision Matrix;

- Determination of sorbent mixtures performance, final selection and optimization.

- Verification of sorbent mixture practicality, stability, and regulatory compliance.

\section{Methodology}

\subsection{Assessment Study}

The first stage of the proposed framework consists of a series of preliminary tests that should be conducted to understand the contamination situation and sediment characteristics. These, together with a thorough and targeted literature review, are meant to aid the planning and design of the main experimental study.

\subsubsection{Site Inspection and Sampling}


Inspection of the site surroundings, historical industrial activities in the area, current land use, human establishment, vegetation species and growth conditions, and groundwater hydrology (elevation changes and seepage points) should elucidate the extent and potential migration path of the contaminants and the most suitable sampling locations. Representative sampling of sediments can require different techniques depending on the type of fluvial system. The following objectives should be achieved by the chosen sampling technique: minimize sample disturbance, ensure samples are representative and independent of sampling point, access only to mobile sedimentation depth, efficient sampling regardless of the type of sediment, simple storage after sampling, and prevention of chemical reactions due to sampling (EMIS, 2001).

\subsubsection{Characterization}

Determination of the elemental composition of sediments is the first step to identify the main heavy metal contaminants present in the sediment. Mineralogical composition of the sediments can help in understanding the how contaminants interact with the material and in which form they might be present (e.g. adsorbed to matrix minerals or as precipitates). Surface water and porewater (interstitial water extracted from the wet sediment) are tested for quantification of the contamination extent and natural mobility of the contaminants; these data form a basis for comparison of sorbent performance. Table 1 presents examples of typical analytical techniques used for these characterization tests.

\subsubsection{Contaminant Mobility Test}

The first objective of this test is to determine the equilibrium concentration of the heavy metals when the sediment is re-suspended in water. The result can be compared against the porewater value measured directly from freshly sampled sediment slurry, to evaluate whether the sediment will release heavy metals into the liquid phase when re-suspended. The results also serve as base case values for remediation performance assessment. The test consists in leaching the sediments with deionized water solution (MilliQ, $18.2 \mathrm{ohm}$ ), either pure, lightly ionized (e.g. $0.01 \mathrm{M} \mathrm{CaCl}_{2}$ ), or dosed with extractants such as $0.1 \mathrm{M} \mathrm{Ca}\left(\mathrm{NO}_{3}\right)_{2}, 0.05 \mathrm{M}$ EDTA, $0.43 \mathrm{M}$ HOAc and $0.1 \mathrm{M} \mathrm{HCl}$ (Chen et al., 2000); these dosages are chosen to adjust the ionic content to more realistic levels in groundwater or to expose the sediments to harsh scenarios that may be found in natural environments.

It is also useful to appraise the overall leachable heavy metal content in the sediments to determine the true sorption capacity of the sorbents. Methods for determining potentially mobile contaminant concentration from soil and sediments vary from chemical modeling to analytical detection (D'Amore et al., 2005). The total contaminant re-supply can be inferred from the metal speciation, which can be determined using sequential selective extractions (Sipos et al., 2008; Zhang and $\mathrm{Pu}, 2011$ ), the purpose of which is to fractionate contaminants into categories (exchangeable, bound to carbonate, bound to iron and manganese oxides, bound to organic matter, residual) that are related to their availability and mobility (Tessier et al., 1979, BCR). These, and other more precise methods to determine heavy metal speciation, such as EXAFS, are 
interesting from a scientific perceptive, but a detailed speciation analysis is not always required. For the purpose of sorbent selection and optimization, which is based on systematic and repetitive experimentation, a more practical approach to obtain a reasonable estimate for dosage calculations is a contaminant supply totalization test. It consists in leaching the sediment at a fixed (pH/Eh-stat), more acidic $\mathrm{pH}$ than the original sediment $\mathrm{pH}$ (e.g. $\mathrm{pH} 4$ ), the objective being to use a $\mathrm{pH}$ value that will release the more mobile contaminant fractions while not truly leaching the more stable matrix phases.

\subsubsection{Literature Review and Benchmarking}

Once the type of contaminants and the degree of contamination are determined, it is important to benchmark and survey the literature for the suitable adsorbents, their most common application conditions, and ideally, though not always available or precisely defined, their application dosage (e.g. grams sorbent per kilogram of sediment). The selection of the most appropriate sorbent for the remediation problem in question depends on several factors. One is the contamination characteristics; different metals require different sorbent characteristics. For example, a differentiation must be made between cationic contaminants (e.g. $\mathrm{Ba}, \mathrm{Cd}, \mathrm{Cu}, \mathrm{Ni}, \mathrm{Pb}$, $\mathrm{Zn}$ ) and oxyanionic contaminants (e.g. As, Mo, Sb, Se, V); for which specific corresponding adsorption or precipitation sites are needed. Another important factor is practicality. Many novel complex sorbents have been reported in literatures (Gao et al, 1995, Katsou et al, 2011, Kuo et al, 2011) ; however most are far from industrial implementation, due to unfavorable technical aspects, economics, or raw material availability. Thirdly, some waste-turned-sorbents (WTS) have shown great potential as they are acclaimed to have the benefits of being economical, available and sustainable, however, public perception and government regulations may severely limit the opportunity to use such materials.

\subsection{Feasibility Study}

Upon selection of potential sorbents, the second stage of the framework aims at testing their interaction with the contaminants and sediments, both to evaluate their performance, and to verify or extend the information collected from literature. The series of experimental tests culminates in the decision matrix that establishes the formulation of sorbent mixture compositions and their required dosages, to be tested in the subsequent stage.

\subsubsection{Sorption Isotherms}

The sorption isotherm allows estimation of the maximum sorption capacity, and sorption capacity at the equilibrium concentrations of porewater; these values are crucial for estimation of sorbent dosage needed to achieve a desired solution concentration. Isotherms are also useful for prediction of sorbent lifespan, allowing for estimation of sorbent replacement frequency to maintain the desired solution concentration over time, taking the additional contaminants emanating from polluted groundwater or upstream source into account. 
Since the sorption theory is not fully understood, and is very specific to a particular system (liquid/solid/solute), isotherms must be obtained experimentally at the conditions most likely to be encountered in the field application (concentration range, temperature, $\mathrm{pH}$...). A popular and robust adsorption isotherm equation for liquid-solid systems is the Langmuir isotherm (Langmuir, 1916). The Langmuir equation (1) is shown below, where $c=$ concentration in solution (e.g. $\mathrm{mg} / \mathrm{L}$ ); $D=$ loading on solids (e.g. g/tonne); and $k$ and $D_{m}$ are empirically derived constants, representing respectively the maximum adsorption capacity and the reaction rate.

$$
D=\frac{D_{m} k c}{1+k c}
$$

Experiments to obtain data points for fitting of the Langmuir equation can be carried out with equal masses of sorbent in aqueous solutions of varying concentrations of heavy metals of interest (e.g. 1 to 100 ppm) (Johnson, 1990; Angove et al., 1999; Banat et al., 2000; Smičiklas et al., 2008; Asta et al., 2009; Zhang et al., 2010) to determine the equilibrium heavy metal concentrations (adsorbed and in solution). Concentration values should be chosen to produce final equilibrium concentrations in the range desired after sorbent addition to the contaminated sediments. Commercially available standard solutions of each element of interest, or their respective salts, can be used to make up the test solutions. Sorbent dosage compatible with expected sorption capacities from literature should be used; slurry are stirred or shaken at a fixed $\mathrm{pH}$ (pH-stat) over a period of time (e.g. 48 hours) and the filtrate is analyzed for the heavy metal concentrations. To assess competition for adsorption sites, multi-element solutions can also be prepared and tested.

\subsubsection{Individual Sorption Test}

Individual sorption tests are conducted to understand the adsorption behavior of each individual sorbent in contact with the contaminated sediments, and to confirm the expected performance based on benchmarked literature. The sorption tests consist in mixing the porewater and the untreated sediment at a specific liquid-to-solid ratio (L/S) ratio (e.g. 5), together with varying amounts of single sorbents (e.g. 5, 10 and $50 \mathrm{~g} / \mathrm{l}$ ), aiming to cover at least one order of magnitude of the sorption capacity ranges reported in literature. The $\mathrm{pH}$ should be measured over time to determine the $\mathrm{pH}$ controlling and buffering capacities of the sorbents, and to relate to the behavior of heavy metals in solution, as $\mathrm{pH}$ is an important controlling factor of solubility. The mixtures should be agitated for a sufficiently long period to ensure suitable equilibrium (e.g. three to ten days), with intermittent sampling and $\mathrm{pH}$ measurement to obtain kinetic information. Filtrates are tested to determine equilibrium heavy metal concentrations in solution and sorbent performance (i.e. percent reduction of porewater heavy metal concentration). The resulting data is used to estimate sorbent mixture compositions for use in the later testing stage.

\subsubsection{Sorbent Selection Decision Matrix}


Multi-element sorption is vastly complex, and the effect is compounded by the challenge of performing sorption in a multi-phase system containing a solid phase that is able to replenish the solution upon contaminant removal. It is expected that each sorbent is incapable of achieving the desired performance for all heavy metals. The purpose of the aforementioned tests is to evaluate the individual sorbent performance with the sediment. To identify the optimal sorbent mixtures, a more systematic methodology is needed to quantify these results and provide better guidance for the ideal composition and dosage of the optimal sorbent mixture.

Herein a Decision Matrix designed to incorporate the measured effects and to estimate optimal composition of the sorbent mixtures for the subsequent experimental phase is presented. Four main criteria are used to analyze the individual sorption test results, with scores being awarded based on performance:

i) Adsorption performance relates to the adsorption performance of the sorbent for each target heavy metal, decoupled from precipitation mechanism based on $\mathrm{pH}$ change:

- score of $\mathbf{- 1}$ (where additional contaminants are brought into solution),

- score of $\mathbf{0}$ (no change in porewater concentration),

- score of $\mathbf{1}$ or $\mathbf{2}$ (depending on extent, where contaminant removal is dominated by adsorption mechanism).

ii) Precipitation performance relates to precipitation performance induced by the sorbent for each of the target heavy metals:

- score of $\mathbf{- 1}$ (where additional contaminants are brought into solution),

- score of $\mathbf{0}$ (no change in porewater concentration),

- score of $\mathbf{1}$ or $\mathbf{2}$ (depending on extent, where contaminant removal is dominated by precipitation mechanism).

iii) $\mathrm{pH}$ effect relates to how much $\mathrm{pH}$ change is caused by use of the sorbent (depends largely on the natural $\mathrm{pH}$ of the sorbent and its buffering capacity):

- score of $\mathbf{0}$ (no $\mathrm{pH}$ change),

- score of $\mathbf{1}$ or $\mathbf{2}$ (moderate to significant $\mathrm{pH}$ change).

iv) $\mathrm{pH}$ suitability describes the most suitable operating $\mathrm{pH}$ range of the sorbent (based on literature findings); for instance, sorbents that release $\mathrm{H}^{+}$groups during adsorption are more suitable for operation at higher $\mathrm{pH}$ (e.g. greater than 5), while sorbent with large buffering capacity are suitable for wide $\mathrm{pH}$ range use.

The scores from the Decision Matrix are aggregated to provide an overall performance score that is used to select sorbent mixture component compositions. Table 2 illustrates the tabulation for a hypothetical example.

Selection of the best sorbent from the Decision Matrix is meant to be based predominantly on the highest scores; however it is still important to take the geochemical system into account. For instance, simply selecting the highest scoring sorbents may overlook the fact that sorption of a particular heavy metal, amongst the pack, is not addressed, or leaching of a heavy metal that is not problematic previously. In these cases, the incorporation of lower scoring sorbents may be needed to complete the treatment. 
The next step in determining sorbent mass composition and dosage is the determination of the contribution level of each sorbent in the adsorption of target heavy metals. The contribution level is an arbitrary measure defined as the percentage of the overall score of a mixture that is attributed to each sorbent. For example, in the case of mixture A shown in Table 3, Sorbent 1 has an individual score of 4 out of an overall mixture score of 9 (the sum of the scores of individual sorbents that make up the mixture), therefore its contribution level is $44 \%$. It is important to note that the mixture score is meant to provide a denominator for contribution calculation; the highest score does not necessarily indicate the best performance.

The exact mixture compositions (in weight percentage) are determined based on sorption isotherm test results, which provide guidance on the sorbent capacities at the operating concentration range. The final sorbent mixture composition and dosage rates to be used in the Performance Study are selected using the calculation procedure described in Table 4.

\subsection{Performance Study}

In the third stage of the remediation framework, the sorbent mixtures are tested to confirm their expected performance, and are optimized if necessary. The decision at this stage must be made with regard to the feasibility of applying the mixtures in the field, most importantly by assessing their long term stability and conformation to regulations with respect to material use in natural environments.

\subsubsection{Sorbent Mixture Performance Test}

With a selection of potential optimum sorbent mixtures compiled, batch adsorption tests are performed to confirm predicted performance and select the most appropriate mixture. Sorbent mixtures are added to a mixture of sediment in porewater at the selected sorbent mixture to sediment ratios. This test determines the equilibrium heavy metal concentrations in solution, the adsorption performance and the capacity of each sorbent mixture. The experimental duration should be long enough to achieve reliable equilibrium (e.g. three to ten days); the solution $\mathrm{pH}$ remains at natural levels for the duration of the test. Analysis of the filtered solution will elucidate whether the desired performance (\% removal compared to porewater values, or drop below regulated limits) has been reached. It is also important to assess whether the equilibrium $\mathrm{pH}$ value is acceptable (near the natural $\mathrm{pH}$ of the site and/or at the ideal $\mathrm{pH}$ for contaminant immobilization) or if additional buffering agents are required. It is possible that not all sorbent mixtures achieve the predicted performance, thus sorbent mixtures that fall short can be eliminated and/or sorbent mixture compositions and dosages can be refined and re-tested.

\subsubsection{Sorbent Mixture Refinement and Optimization}

Based on the first round of sorbent mixture testing, choices can be made on which sorbent mixtures meet the expected performance, which fall short but offer possibility of improvement, and which perform unexpectedly poorly and should be disposed of. The following are some remarks on what criteria can be used for evaluation: 
1. Desired percentage removal achieved: no dosage or composition change required; assess regulatory requirements for application and material cost and availability.

2. Removal performance falls short: does it make sense to increase dosage or modify sorbent composition? If so, conduct another experimental round.

3. Removal performance exceeds expectation: reduce sorbent dosage or change sorbent composition to reduce material cost.

4. Removal performance attributed to precipitation more than adsorption: change sorbent composition to promote adsorption or eliminate sorbent mixture if unfeasible.

5. Increased concentration of one or more contaminants: change sorbent composition to minimize detrimental effect or eliminate sorbent mixture if unfeasible.

\subsubsection{Stability and Regulation}

Finding an optimum sorbent mixture for a specific remediation problem is a challenging endeavor, but it is not the final step if the sorbent is to be applied in the field. Numerous regulations govern the use of materials in the environment, and many road blocks can slow down or even inhibit a particular solution from actually being used, despite the positive laboratory test results. To increase the chances of success, due diligence is paramount. This means being aware of the regulations from the beginning of a project, and applying them to the working materials for the duration of the project, not simply at the end. In this manner the regulations act as boundary conditions that guide the research and development, rather than barriers that impede innovation. The following are a selection, by no means complete, of consideration to be taken:

Adsorption stability: adsorption tests typically are conducted for several hours up to several days, but in field application, sorbents are meant to stabilize contaminants for extended periods of time, and ideally permanently. Some approaches to test the stability of sorbents include conducting batch desorption tests (Mustafa et al., 2004; Rao et al., 2006; Dimovic et al., 2009), and lysimeter tests (Hu and Luo, 2007; Lo and Liao, 2007; Karnchanawong and Limpiteeprakan, 2009). The basic idea is to dilute a sample of spent-sorbent, or a stabilized mixture of sediment and sorbent, in fresh solution (e.g. pure water, groundwater, river water) and measure the release of contaminants, either in a batch experiment, or continuously (lysimeter/column). This helps to determine the sorption stability of the mixture over long term, and its efficiency in containing the contamination site.

Sorbent mixture selection: waste residues are a major point of interest for sorbent synthesis from sustainability and market availability perspectives, however, they can often carry hazardous contaminants from its original production source, including heavy metals (e.g. combustion fly ash (Reddy et al., 2005), organic fractions (e.g. municipal waste incineration bottom ash (Rendek et al., 2006), carcinogens (e.g. clinoptilolite-containing zeolite (Temel and Giindogdu, 1981)) and radioactive species (e.g. red mud (Somlai et al., 2008)). For this reasons, environmental regulation agencies may be skeptical about applying such materials in the natural environment for long-term, and often dispersive, uses. Therefore it is essential at time of research and development to maintain close communication with authorities to know 
what regulations must be met. It is also crucial, from a project management perspective, to proactively check whether the preferred sorbents met such regulations during the course of development of the remediation solution.

\section{Case Study: Contaminated Sediment Treatment}

The strategic framework herein established is put to use in the development of a remediation solution to contaminated brook sediments in Northern Belgium. Sediment samples used in this study originate from an area affected from historical pollution due to metallurgical activities (Vanbroekhoven et al., 2008) that have contaminated the soil, groundwater and the sediments in small brooks (Figure 2) that discharge into larger fluvial systems. In the study area, chemical precipitates derived from groundwater-associated $\mathrm{Fe} 2+$ seeping into the overlying surface water significantly contribute to the composition, concentration, and fluxes of suspended sediment (Vanlierde et al., 2007). These Fe2+ enriched groundwaters relates to the subsurface water percolation trough glauconite bearing Tertiary sands. The sampling points were chosen at locations that were primarily exposed to contaminated groundwater seepage. This section details each stage of the framework, presenting conceptual and experimental results, analysis and decisions made during the course of the work.

\subsection{Assessment Study}

\subsubsection{Site Inspection and Sampling}

Sediment samples were collected from the upper most layer $(<10 \mathrm{~cm})$ of the submersed river bed, avoiding mixing with the underlying sandy substrate. The sediments were stored in waterfilled air-tight sealed plastic containers, and refrigerated to minimize physicochemical and biologically driven changes. Likewise, surface water samples were also collected. Prior to use sediments were filtered through a coarse sieve to remove leaves and other organic and inorganic debris. For collection of porewater (mechanically entrained water), a portion of the sediments was centrifuged and filtered immediately after the sampling.

\subsubsection{Characterization and Contaminant Mobility}

The main heavy metal contaminants in the sediment are $\mathrm{As}, \mathrm{Cd}, \mathrm{Pb}$ and $\mathrm{Zn}$, and the values (measured by XRF, ICP-MS and AAS) are presented in Table 5.

The matrix composition was found to be made up of $\mathrm{Fe}$ (30.1\%), Si (11.7\%), S (5.2\%) and $\mathrm{Al}$ (4.5\%). The high $\mathrm{Fe}$ and low $\mathrm{Si}$ concentrations relate to the dominantly authigenic nature of the sampled brook sediments. The Al content can be regarded as a measure for its clay content, and $\mathrm{S}$ likely relates to the possible existence of Fe-sulphides next to the Fe oxi/hydroxides, each defining micro-environmental sub-settings in the brooks. The sediment was found to be highly amorphous, with expected clay and low sand content. Quartz, goethite and illite were the crystalline phases confirmed, in agreement with the Si and Fe content. Concentrations of zinc 
and cadmium in the sediment are particularly high, though arsenic and lead are present in significant amounts as well. The high concentrations are likely related to the co-precipitation of these elements with Fe-sulphides and Fe oxi/hydroxides.

The porewater of the sediment and the surface water were analyzed to determine the concentration of the heavy metals in solution. Results are presented in Table 5, together with $\mathrm{pH}$ values. Surface water values for $\mathrm{Cd}$ and $\mathrm{Zn}$ are lower than in porewater due to the higher $\mathrm{pH}$ of surface water, which in turn causes higher $\mathrm{As}$ and $\mathrm{Pb}$ concentrations in the surface water. In Table 5, values of contaminant mobility, performed with $0.01 \mathrm{M} \mathrm{CaCl}_{2}$, and contaminant supply totalization, performed at $\mathrm{pH} 4$ with $\mathrm{HNO}_{3}$ adjustment, are also shown.

\subsubsection{Literature Review and Benchmarking}

The investigated site contains manifold heavy metals, which possess different chemical properties that control their mobility and toxicity, therefore no single additive was expected to immobilize all inorganic contaminants. In such case, a composite sorbent mixture is needed to immobilize co-existing heavy metals in multi-contaminated sediment (Qian et al., 2009). Three adsorbents, goethite, hydroxyapatite (HAP) and natural zeolite (N. Zeolite), were identified as having shown promising results in the literature, and therefore were selected for use in this study. It was also of interest to investigate the possibility of utilizing the synthesized waste-turnedsorbent materials, which combine the benefits of low-cost materials valorization, environmental hazard stabilization, and widely available supply. Two made waste-turned-sorbents were used in this study, namely a zeolitic-type sorbent synthesized from municipal solid waste incineration bottom ashes (MSWI-BA), which was prepared in-house (Chiang et al., in press), and a water treatment process derived waste solid commonly referred to as water treatment residuals (WTRs), also previously reported by Sarkar et al. (2007) and Nielsen et al. (2011). These sorbents will hereafter be referred to as WTS-1 and WTS-2, respectively.

The performance of the selected sorbents based on literature search findings is summarized in Table 6 . Both the greatest and smallest maximum capacity values reported are shown to illustrate the variability in available results, as researchers often work with significantly different systems, from synthetically made solutions to contaminated sediment/soil treatment. These values provide a rough guideline of expected performance, and should be compared with in-house results on sorption performance at the most relevant process conditions (individual batch tests and isotherm tests, discussed in the next section).

\subsection{Feasibility Study}

\subsubsection{Sorption Isotherm}

Experiments were carried out with sorbents in aqueous solutions of varying concentrations of $\mathrm{As}, \mathrm{Cd}, \mathrm{Pb}$ and $\mathrm{Zn}$ (1 to $100 \mathrm{mg} / \mathrm{l})$ at the natural $\mathrm{pH}$ of the sediment porewater. Table 7 demonstrates the maximum sorption capacities $\left(D_{m}\right)$ and the sorption capacities $\left(D_{90 \%}\right)$ at the $90 \%$ removal concentration $(27 \mathrm{mg} / \mathrm{l})$ for the five sorbents with respect to zinc. Since zinc is the 
dominating contaminant in the system (by a scale of 100 times), its capacity values were used for sorbent dosage estimation for the sorbent mixture tests in the next stage.

\subsubsection{Individual Sorption Test}

Batch sorption tests were performed by mixing the sediment slurry with each sorbent at three different ratios, $0.05,0.1$ and $0.5 \mathrm{~g} / \mathrm{l}$. Mixtures were agitated in sealed plastic bottles on a vibrating table for seven days. Table 8 summarizes the main findings of these experiments, including the maximum removal performances for the heavy metals, typically achieved with the highest sorbent dosage. In certain cases, As leaching was observed with increased $\mathrm{pH}$, and the level worsened when the dosages was at the highest. These results suggest HAP and WTS-2 are the best performing sorbents and may be interchangeable, while Goethite and Natural Zeolite appear useful for controlling As concentrations. The performance of WTS-1 is difficult to assess given it performs very well for $\mathrm{Zn}$, but suffers from insufficient removal of $\mathrm{Cd}$, significant $\mathrm{pH}$ increase, and As leaching. These results and observations are used in the next step to tabulate the Decision Matrix.

\subsubsection{Sorbent Selection Decision Matrix}

The performance criteria are utilized to determine potential sorbent mixtures, composed of a combination of commercially available sorbents, goethite, natural zeolite and hydroxyapatite; and waste-turn-sorbents, WTS-1 and WTS-2. Based on individual sorbent tests (Table 8) and literature benchmarking, the performance of each sorbent in terms of adsorption and precipitation efficiency, $\mathrm{pH}$ effect and $\mathrm{pH}$ suitability were assessed. This assessment led to the scoring of the sorbents as shown in Table 9. The overall scores (bottom row) are used to select several sorbent mixture compositions for further testing (Table 10). Sorbent compositions were chosen to cover three categories: (i) commercially available sorbents only; (ii) partial substitution of HAP with waste-turned-sorbents; and (iii) full substitution of HAP with waste-turnedsorbents. As previously mentioned, the percentage values shown are contributory percentages on the adsorption performance by each sorbent, and are used for calculation of sorbent mixture composition and dosage later on.

\subsection{Performance Study}

\subsubsection{Sorbent Mixture Performance Test}

Batch adsorption tests based on the dosages and the compositions shown in Table 11 were performed over three days to determine sorbent mixture performance, and the results are shown in Fig. 3 and Fig. 4a.

Sorption mixtures A and B, which are made up of commercial sorbents, failed to meet the 90\% removal expected, reaching between $60 \%$ and $80 \%$ removal for $\mathrm{Zn}$ and $\mathrm{Cd}$. The remaining mixtures, C, D, E and F achieved higher than $90 \%$ removal of $\mathrm{Zn}$ and $\mathrm{Cd}$. 
However, mixture $\mathrm{A}$ and $\mathrm{B}$ effectively controlled $\mathrm{As}$ and $\mathrm{Pb}$ concentrations to lower values than the porewater, whereas mixtures $C, D$ and $E$ resulted in higher concentration values than the original porewater, signifying an undesired effect. For mixture $\mathrm{C}$, this undesired effect can be directly linked to the high final $\mathrm{pH}$ value of nearly 7.5, which contributes to leaching of As(III) (Chiang et al., in press). Mixture E leached the most As; the negative effect is likely attributed to a poor performance of goethite. Mixture $F$ has the best As performance indicating the superior As sorption by Natural Zeolite. Performance for $\mathrm{Pb}$ was satisfactory for all sorbent mixtures, in particular mixtures $\mathrm{A}, \mathrm{B}$ and $\mathrm{F}$.

Overall, mixture F was the most successful mixture. Other mixtures performed close to expectation based on the design calculations for mixture dosages and compositions. Clearly the structured research framework facilitated the achievement of results near the desired targets. To further improve performance of the sorbent mixtures and find the optimal composition and dosage, further refining took the following reasoning:

- Commercial sorbent mixtures: Although not the best performing sorbent mixtures, it was decided not to write them off as these sorbents are already regulation-established and may have more realistic chances of field application. Mixture B outperformed mixture A, by delivering a more leveled and efficient removal. The efficiency can be improved by increased HAP content and the mixture mass can be reduced by decreasing Natural Zeolite content.

- Partial Substitution: Mixture D performed better, by delivering a well rounded performance. For refinement, a decrease of WTS-2 to decrease $\mathrm{pH}$ and As leaching, and an increase in Natural Zeolite to help reducing As leaching can be implemented.

- Full substitution: Mixture F performed best. A decrease in dosage is needed to lower the equilibrium $\mathrm{pH}$.

\subsubsection{Sorbent Mixture Refinement and Optimization}

Combining the assessments made from the first batch of sorbent mixture performance tests, three sorbents mixtures were selected to continue forward, one taken from each category: B, D and F. In particular, goethite and WTS-1 were eliminated as their performances were deemed insufficient or detrimental for this particular application. The compositions of the refined sorbent mixtures are shown in Table 12.

The refined performance of the sorbent mixtures is shown in Fig. $4 \mathrm{~b}$ (for $\mathrm{pH}$ ) and Fig. 5. (for heavy metals)Mixtures B1 and B2 have improved efficiency to around $80 \%$ for $\mathrm{Zn}$ and close to $90 \%$ for Cd. Mixtures D1, D2, F1 and F2 deliver 90\% or better removal efficiency for both Zn and $\mathrm{Cd}$. All mixtures show sufficient $\mathrm{As}$ and $\mathrm{Pb}$ control compared to the original sediment porewater concentration. Fig. $4 \mathrm{~b}$ shows the equilibrium $\mathrm{pH}$ values for each refined sorbent/sediment mixture. Mixtures B1 and B2 have the lowest $\mathrm{pH}$ increase, while mixtures D1, $\mathrm{D} 2, \mathrm{~F} 1$ and $\mathrm{F} 2$ have higher $\mathrm{pH}$ increases, but the increases are less pronounced than in the unrefined tests, and are within the acceptable range. 
The refined sorbent mixtures have proven to deliver robust performance. Given the fact that each category of sorbent mixture has its own advantage: commercially available (easy to obtain), partial substitution (effective performance), full substitution (cost efficiency), three mixtures, one from each category, were selected for the stability and regulation tests:

* Commercially available: Mixture B2 selected. Although Mixture B1 slightly outperformed B2, B2 has lower As concentration and pH.

* Partial substitution: Mixture D1 selected. Mixture D1 and D2 both deliver outstanding performance; D1 is selected for its lower $\mathrm{pH}$ value.

* Full substitution: Mixture F1 selected. Mixture F2 is eliminated due to higher pH.

\subsubsection{Stability and Regulation}

Long term stability test is carried out with each selected sorbent mixture together with sediment, and with the sediment itself, at natural $\mathrm{pH}$. After ten days of shaking, the contaminant concentrations are measured to determine the long term stability of the adsorbed heavy metals. The long stability results are summarized in Fig. 6. The sediment itself is unstable, and progressively releases $\mathrm{Cd}, \mathrm{Pb}$ and $\mathrm{Zn}$. The addition of the sorbent mixtures effectively reduces $\mathrm{Cd}$ and $\mathrm{Zn}$ leaching, and stabilizes $\mathrm{Pb}$ leaching over the ten day period. The As levels of all solutions, decreased over time, indicating the initial high levels in the sediment were induced by initial dilution and $\mathrm{pH}$ change but become stable over time. Mixture B2 showed the least stability for $\mathrm{Pb}$ and least satisfactory performance for $\mathrm{Cd}$ and $\mathrm{Zn}$, therefore it, while being the only readily commercially available mixture, is the least preferred choice for scale-up.

To ensure the sorbent mixtures conform to the Flemish non-molded building materials VLAREA regulations, the following tests were performed: CMA 2/IIA.3 Microwave Digestion, and Vlarebo Leaching test. The CMA 2/IIA.3 Microwave Digestion test determines the compositions of the sorbent mixtures and set upper limits for use. All three sorbent mixtures met the regulation limits. The Vlarebo shake test determines the leaching behavior of materials in pure water by batch leaching test. Several tests were performed: sediment alone, sorbent mixtures alone, and sediment plus sorbent mixtures. It was found that the sediment itself exceeded several regulation limits, especially for $\mathrm{As}, \mathrm{Cd}$, and $\mathrm{Zn}$. All sorbent mixtures were found to meet the regulation limits, therefore are suitable for in-situ remediation use. The combined sediment-sorbent mixtures still exceeded the regulation limits for certain elements, in particular As, Cd and Zn, however at much reduced levels, which for this study were found to be satisfactory, leading to further piloting study for field implementation.

\section{Conclusions}

The proposed framework, encompassing several methods and strategies, proved useful for finding effective sorbent mixtures for the case study discussed. Its application led to a systematic and well structured research and development program, which delivered the required results with sufficient level of detail and confidence. In comparison it was confirmed that a thorough review 
of the available literature is only useful in providing guidance to the most promising remediation solutions, but it alone cannot provide sufficient detail and accuracy for engineering design of a remediation solution to a particular problem, especially in the case of multi-contaminated sediments. The next step in assessment of the proposed solution is an on-site pilot scale testing to confirm the mixture effectiveness and assess sorbent life span. This work provides guidance to researchers in the field of the remediation of heavy metal contaminated sediments, that look to bridge the gap from laboratory research to field application, and that the proposed strategies prove indispensable for environmental management of contaminated sites.

\section{Acknowledgment}

The K.U. Leuven Industrial Research Fund is gratefully acknowledged for funding the knowledge platform for Sustainable Materialization of Residues from Thermal Processes into Products (SMaRT-Pro ${ }^{2}$ ) in which this work was performed. The authors are also thankful for the support provided by OVAM (Public Waste Agency of Flanders) during the execution of the case study.

\section{References}

Angove, M.J., Wells, J.D., Johnson, B.B., 1999. The Influence of Temperature on the Adsorption of Cadmium(II) and Cobalt(II) on Goethite, J. Colloid Interface Sci. 211, 281-290.

Asta, M.P., Cama, J., Martínez, M., Giménez, J., 2009. Arsenic removal by goethite and jarosite in acidic conditions and its environmental implications, J. Hazard. Mater. 171, 965-972.

Balistrieri, L.S., Murray, J.W., 1982. The adsorption of $\mathrm{Cu}, \mathrm{Pb}, \mathrm{Zn}$, and $\mathrm{Cd}$ on goethite from major ion seawater, Geochim. Cosmochim. Acta 46, 1253-1265.

Banat, F., Al-Asheh, S., Mohai, F., 2000. Batch zinc removal from aqueous solution using dried animal bones, Sep. Purif. Technol. 21, 155-164.

Basta, N.T., McGowen, S.L., 2004. Evaluation of chemical immobilization treatments for reducing heavy metal transport in a smelter-contaminated soil. Environ. Pollut. 127, 73-82.

Boisson, J., Ruttens, A., Mench, M., Vangronsveld, J., 1999. Evaluation of hydroxyapatite as a metal immobilizing soil additive for the remediation of polluted soils. Part 1. Influence of hydroxyapatite on metal exchangeability in soil, plant growth and plant metal accumulation, Environ. Pollut. 104, 225-233.

Chen, Z.S., Lee, G.J., Liu, J.C., 2000. The effects of chemical remediation treatments on the extractability and speciation of cadmium and lead in contaminated soils, Chemosphere 41, 235-242.

Chiang, Y.W., Ghyselbrecht, K., Santos, R.M., Meesschaert, B., Martens, J.A., Synthesis of Zeolitic-type Adsorbent Materials from Municipal Solid Waste Incinerator Bottom Ash and its Application in Heavy Metal Adsorption, Catal. Today, in press. 
Corami, A., Mignardi, S., Ferrini, V., 2008. Cadmium removal from single- and multi-metal (Cd $+\mathrm{Pb}+\mathrm{Zn}+\mathrm{Cu}$ ) solutions by sorption on hydroxyapatite, J. Colloid Interface Sci. 317, 402408.

D'Amore, J.J., Al-Abed, S.R., Scheckel, K.G., Ryan, J.A., 2005. Methods for speciation of metals in soils: a review, J. Environ. Qual. 34, 1707-1745.

Dimovic, S., Smiciklas, I., Plecas, I., Antonovic, D., 2009. Kinetic Study of $\mathrm{Sr}^{2+}$ Sorption by Bone Char, Sep. Sci. Technol. 44, 645-667.

Energie- en Milieu InformatieSysteem voor het Vlaamse Gewest (EMIS), 2001. Waterbodem CMA/1/A.3. Available from: http://www.emis.vito.be/sites/default/files/referentie_labo/referentielabo_bodem_CMA_2006 _1-A3.pdf (accessed 16.10.11).

Gao, Y.M., Sengupta, A.K., Simpson, D., 1995. A new hybrid inorganic sorbent heavy metals removal, Water Res. 29, 9, 2195-2205.

Hamidpour, M., Afyuni, M., Kalbasi, M., Khoshgoftarmanes, A.H., Inglezakis, V.J., 2010. Mobility and plant-availability of $\mathrm{Cd}(\mathrm{II})$ and $\mathrm{Pb}$ (II) adsorbed on zeolite and bentonite, Appl. Clay Sci. 48, 342-348.

Hashim, M.A., Mukhopadhyay, S., Sahu, J.N., Sengupta, B., 2011. Remediation technologies for heavy metal contaminated groundwater, J. Environ. Manage., doi:10.1016/j.jenvman.2011.06.009.

$\mathrm{Hu}, \mathrm{N} .$, Luo, Y., 2007. A field lysimeter study of heavy metal movement down the profile of soils with multiple metal pollution during chelate-enhanced phytoremediation, Int. J. Phytorem. 9, 257-268.

Jacobs, P.H., Förstner, U., 1999. Concept of subaqueous capping of contaminated sediments with active barrier systems (abs) using natural and modified zeolites, Water Res. 33, 2083-2087.

Johnson, B.B., 1990. Effect of pH, Temperature, and Concentration on the Adsorption of Cadmium on Goethite, Environ. Sci. Technol. 24, 112-118.

Katsou, E., Malamis, S., Haralambous, K.J., Industrial wastewater pre-treatment for heavy metal sorbent-assisted ultrafiltration system, Chemosphere 82, 4, 557-564.

Karnchanawong, S., Limpiteeprakan, P., 2009. Evaluation of heavy metal leaching from spent household batteries disposed in municipal solid waste, Waste Manage. 29, 550-558.

Kuo, J.H., Lin, C.L., Wey, M.Y., 2011. Effect of particle agglomeration on metals adsorption by Al- and Ca-based sorbents during fluidized bed incineration, Fuel Process. Technol. 92, 10, 2089-2098

Langmuir, I., 1916. The constitution and fundamental properties of solids and liquids. Part I. Solids. J. Am. Chem. Soc. 38, 2221-2295.

Lin, C.-F., Lo, S.-S. Lin, H.-Y., Lee, Y., 1998. Stabilization of cadmium contaminated soils using synthesized zeolite, J. Hazard. Mater. 60, 217-226.

Lin, Z., Puls, R.W., 2003. Potential indicators for the assessment of arsenic natural attenuation in the subsurface, Adv. Environ. Res. 7, 825-834. 
Lo, H.-M., Liao, Y.-L., 2007. The metal-leaching and acid-neutralizing capacity of MSW incinerator ash co-disposed with MSW in landfill sites, J. Hazard. Mater. 142, 512-519.

Motsa, M.M., Mamba, B.B., Thwala, J.M., Msagati, T.A.M., 2011. Preparation, characterization, and application of polypropylene-clinoptilolite composites for the selective adsorption of lead from aqueous media, J. Colloid Interface Sci. 359, 210-219.

Mustafa, G., Singh, B., Kookana, R.S., 2004. Cadmium adsorption and desorption behaviour on goethite at low equilibrium concentrations: effects of $\mathrm{pH}$ and index cations, Chemosphere 57, 1325-1333.

Nielsen, S.S., Petersen, L.R., Kjeldsen, P., Jakobsen, R., 2011. Amendment of arsenic and chromium polluted soil from wood preservation by iron residues from water treatment, Chemosphere 84, 383-389.

Page, G.W., 1997. Contaminated sites and environmental cleanup: international approaches to prevention, remediation, and reuse. Academic Press, San Diego.

Panuccio, M.R., Sorgonà, A., Rizzo, M., Cacco, G., 2009. Cadmium adsorption on vermiculite, zeolite and pumice: Batch experimental studies, J. Environ. Manage. 90, 364-374.

Perić, J., Trgo, M., Medvidović, N.V., 2004. Removal of zinc, copper and lead bynatural zeolite - a comparison of adsorption isotherms, Water Res. 38, 1893-1899.

Qian, G., Chen, W., Lim, T.T., Chui, P., 2009. In-situ stabilization of Pb, Zn, Cu, Cd and Ni in the multi-contaminated sediments with ferrihydrite and apatite composite additives, J. Hazard. Mater. 170, 1093-1100.

Qiu, W., Zheng, Y., 2009. Removal of lead, copper, nickel, cobalt, and zinc from water by a cancrinite-type zeolite synthesized from fly ash, Chem. Eng. J. 145, 483-488.

Rao G.P.C., Satyaveni, S., Ramesh, A., Seshaiah, K., Murthy, K.S.N., Choudary, N.V., 2006. Sorption of cadmium and zinc from aqueous solutions by zeolite $4 \mathrm{~A}$, zeolite $13 \mathrm{X}$ and bentonite, J. Environ. Manage. 81, 265-272.

Rauret, G., López-Sánchez, J. F., Sahuquillo, A., Rubio, R., Davidson, C., Ure, A., Quevauviller, P., 1999. Improvement of the BCR three step sequential extraction procedure prior to the certification of new sediment and soil reference materials, J. Environ. Monit. 1, 57-61.

Reddy, M.S., Basha, S., Joshi, H.V., Jha, B., 2005. Evaluation of the emission characteristics of trace metals from coal and fuel oil fired power plants and their fate during combustion, J. Hazard. Mater. B123, 242-249.

Rendek, E., Ducom, G., Germain, P., 2006. Influence of organic matter on municipal solid waste incinerator bottom ash carbonation, Chemosphere 64, 1212-1218.

Ruggieri, F., Marín, V., Gimeno, D., Fernandez-Turiel, J.L., García-Valles, M., Gutierrez, L., 2008. Application of zeolitic volcanic rocks for arsenic removal from water, Eng. Geol. 101, 245-250.

Sarkar, D., Makris, K.C., Vandanapu, V., Datta, R., 2007b. Arsenic immobilization in soils amended with drinking-water treatment residuals, Environ. Pollut. 146, 414-419.

Shawabkeh, R., Al-Harahsheh, A., Hami, M., Khlaifat, A., 2004. Conversion of oil shale ash into zeolite for cadmium and lead removal from wastewater, Fuel 83, 981-985. 
Sheta, A.S., Falatah, A.M., Al-Sewailem, M.S., Khaled, E.M., Sallam, A.S.H., 2003. Sorption characteristics of zinc and iron by natural zeolite and bentonite, Microporous Mesoporous Mater. 61, 127-136.

Shi, W.-Y., Shao, H.-B., Li, H., Shao, M.-A., Du, S., 2009. Progress in the remediation of hazardous heavy metal-polluted soils by natural zeolite, J. Hazard. Mater. 170, 1-6.

Sipos, P., Németh, T., Kis, V.K., Mohai, I., 2008. Sorption of copper, zinc and lead on soil mineral phases, Chemosphere 73, 461-469.

Smičiklas, I., Onjia, A., Raičević, S., Janaćković, Đ., Mitrić, M., 2008. Factors influencing the removal of divalent cations by hydroxyapatite, J. Hazard. Mater. 152, 876-884.

Somlai, J., Jobbágy, V., Kovács, J., Tarján, S., Kovács, T., 2008. Radiological aspects of the usability of red mud as building material additive, J. Hazard. Mater. 150, 541-545.

Tang, Y., Wang, J., Gao, N., 2010. Characteristics and model studies for fluoride and arsenic adsorption on goethite, J. Environ. Sci. 22, 1689-1694.

Temel, A., Gündogdu, M.N., 1981. Zeolite occurrences and the erionite-mesothelioma relationship in Cappadocia, central Anatolia, Turkey, Mineral. Deposita 31, 539-547.

Tessier, A., Campbell, P.G.C., Bisson, M., 1979. Sequential extraction procedure for the speciation of particulate trace metals, Anal. Chem. 51, 844-851.

Vanbroekhoven, K., Van Roy, S., Diels, L., Gemoets, J., Verkaeren, P. Zeuwts, L., Feyaerts, K., van den Broeck, F., 2008. Sustainable approach for the immobilization of metals in the saturated zone: In situ bioprecipitation. Hydrometallurgy 94, 110-115.

Vanlierde, E., Schutter, J.D., Jacobs, P., Mostaert, F., 2007. Estimating and modeling the annual contribution of authigenic sediment to the total suspended sediment load in the Kleine Nete Basin, Belgium, Sedimentary Geology 202, 317-332.

Villalobos, M., Pérez-Gallegos, A., 2008. Goethite surface reactivity: A macroscopic investigation unifying proton, chromate, carbonate, and lead(II) adsorption, J. Colloid Interface Sci. 326, 307-323.

Wang, S., Mulligan, C.N., 2006. Natural attenuation processes for remediation of arsenic contaminated soils and groundwater, J. Hazard. Mater. B138, 459-470.

Warren, L.J., 1981. Contamination of sediments by lead, zinc and cadmium: a review, Environ. Pollut. (B) 2, 401-436.

Yadanaparthi, S.K.R., Graybill, D., vonWandruszka, R., 2009. Adsorbents for the removal of arsenic, cadmium, and lead from contaminated waters, J. Hazard. Mater. 171, 1-15.

Zhang, M., Pu, J., 2011. Mineral materials as feasible amendments to stabilize heavy metals in polluted urban soils, J. Environ. Sci. 23, 607-615.

Zhang, Z., Li, M., Chen, W., Zhu, S., Liu, N., Zhu, L., 2010. Immobilization of lead and cadmium from aqueous solution and contaminated sediment using nano-hydroxyapatite, Environ. Pollut. 158, 514-519. 


\section{List of Figures}

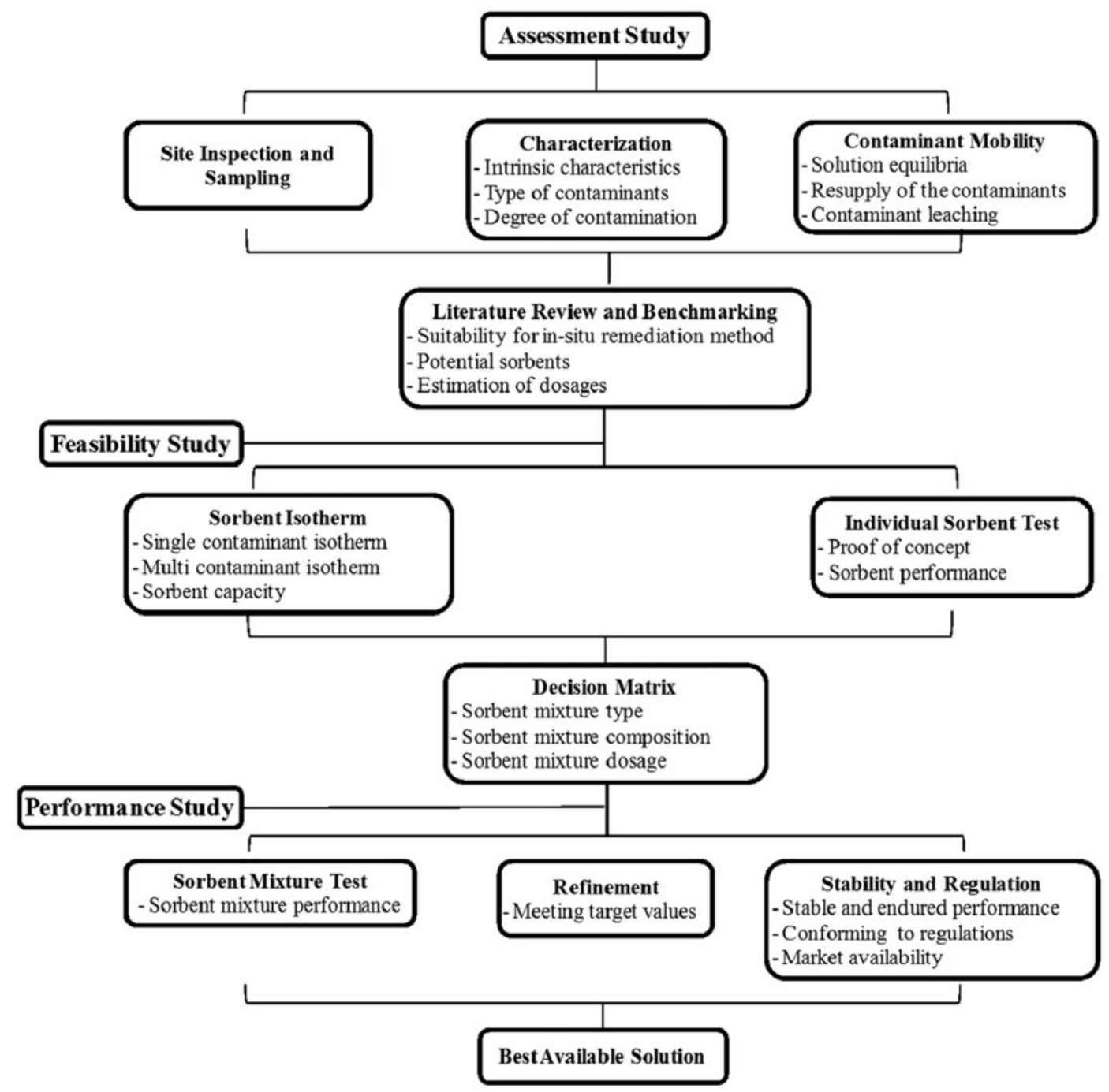

Fig.1. Framework of heavy metal remediation assessment strategy. 


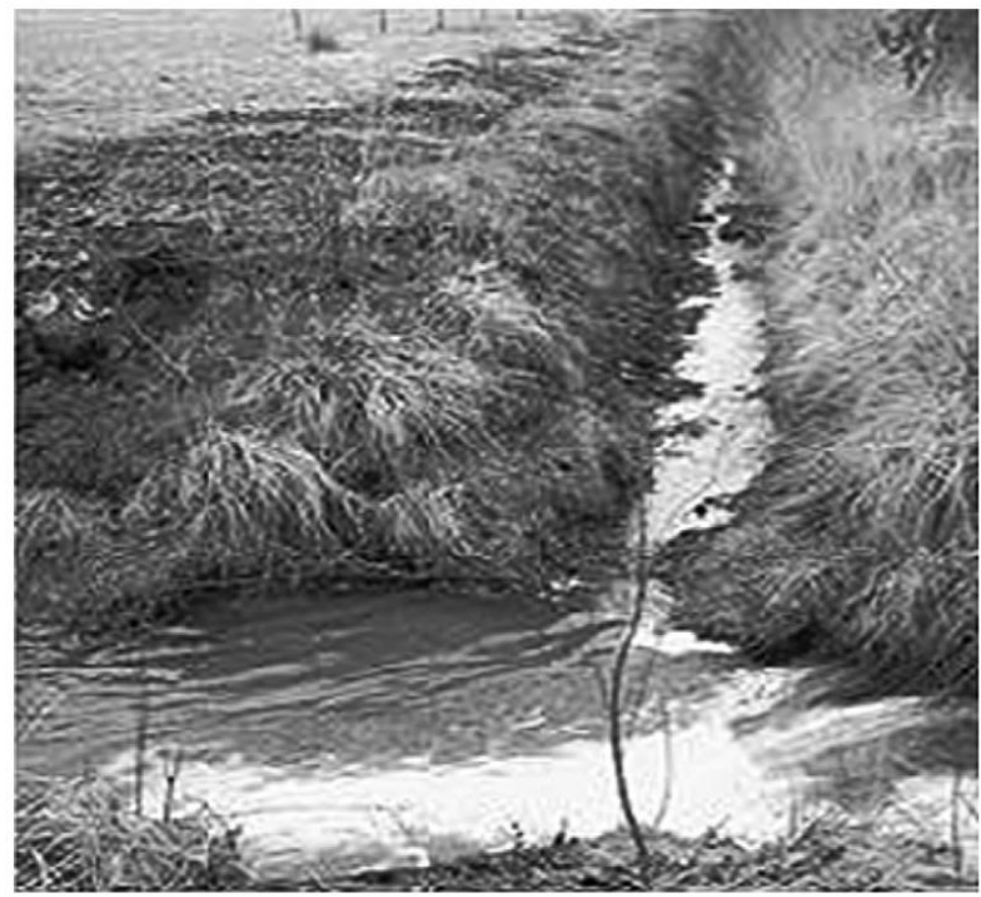

Fig. 2. Contaminated sediment brook in Northern Belgium.
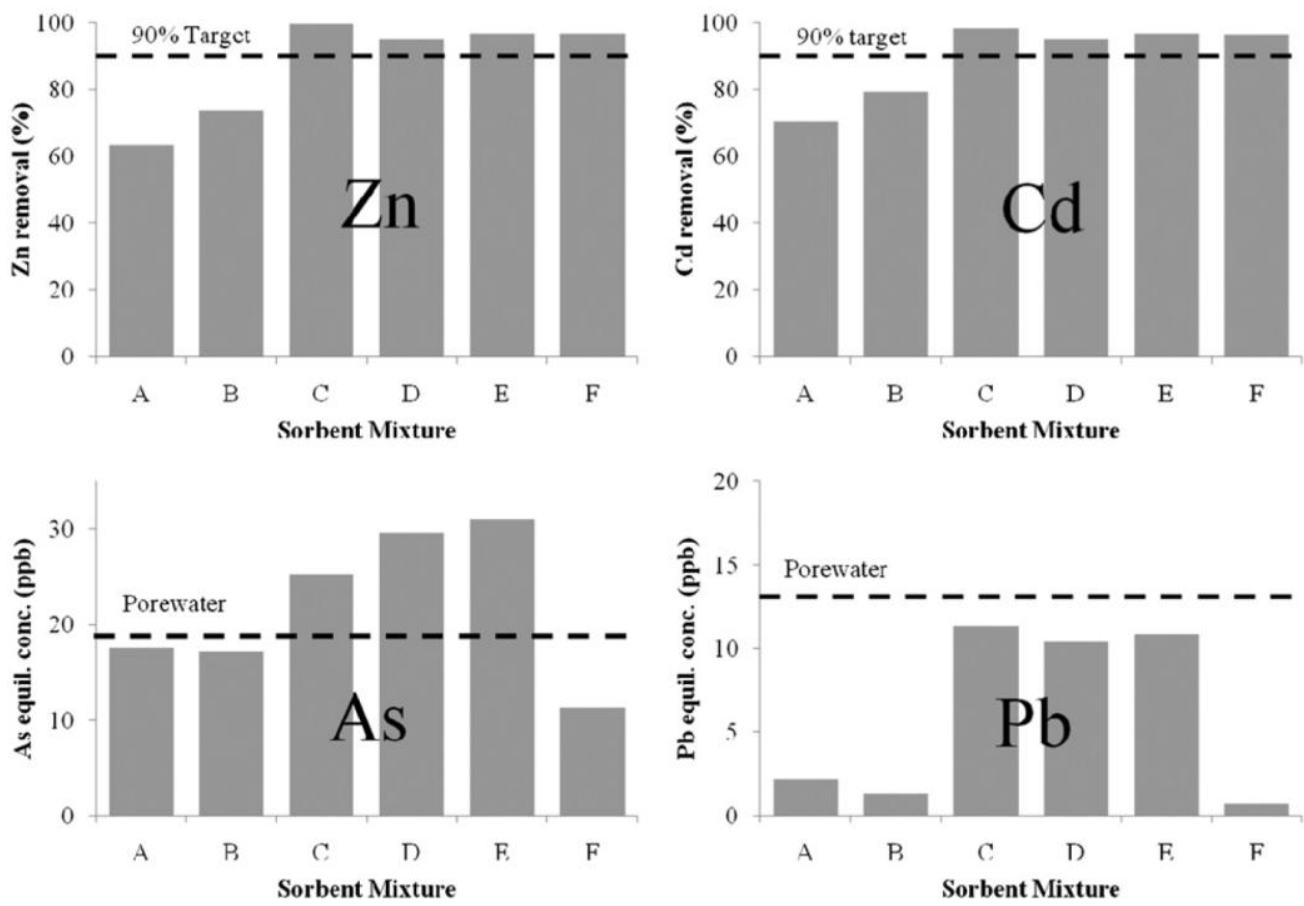

Fig. 3. Performance of optimum sorbent mixtures for adsorption of $\mathrm{As}, \mathrm{Cd}, \mathrm{Pb}$ and $\mathrm{Zn}$. 

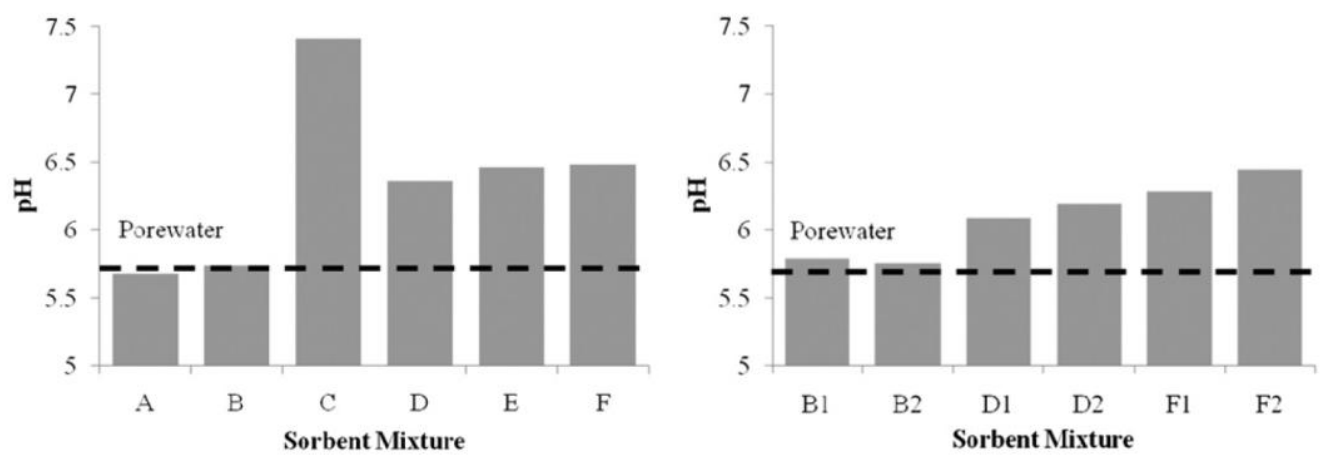

Fig. 4. Equilibrium $\mathrm{pH}$ of sorbent mixtures combined with sediment: a. Before refinement, b. Refined $\mathrm{pH}$ performance.
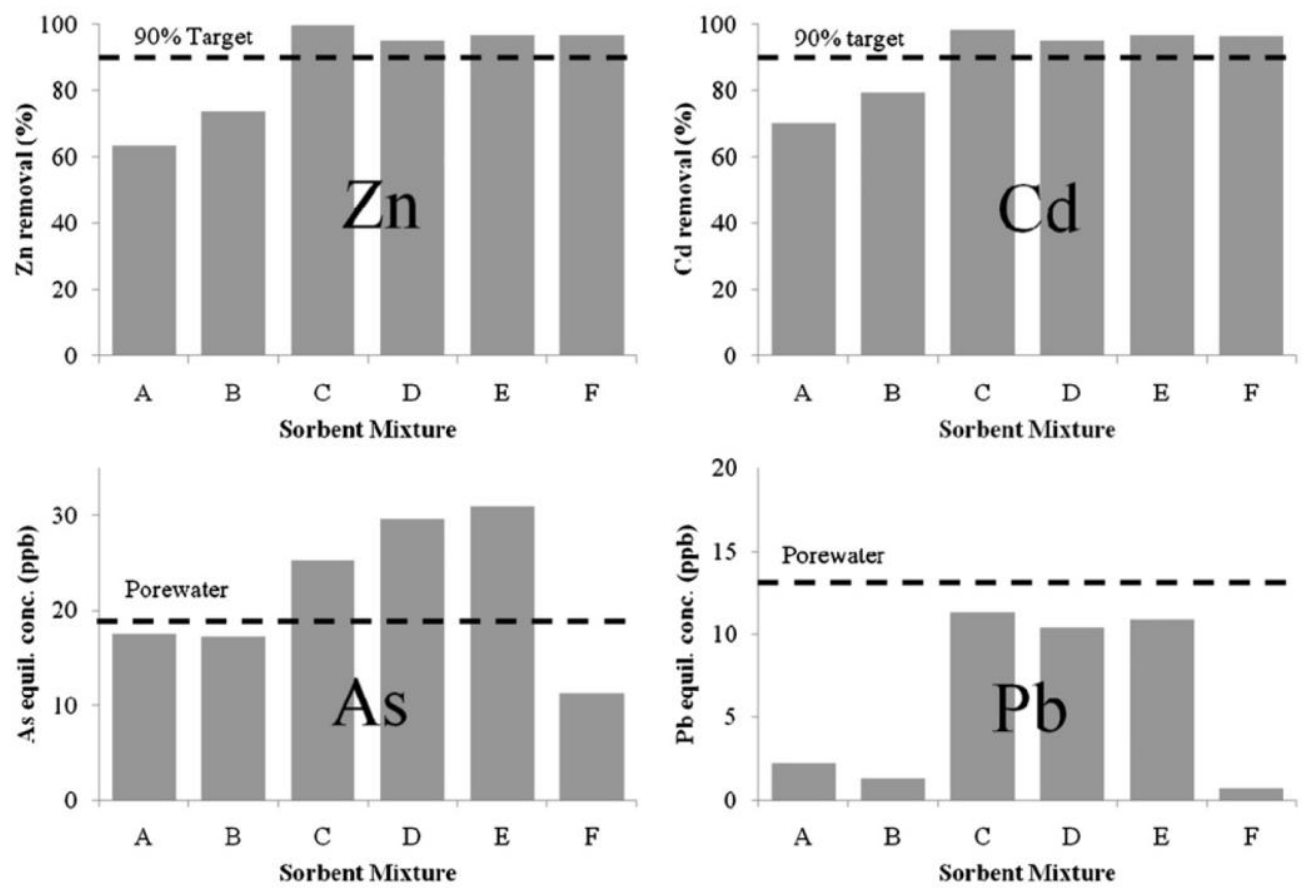

Fig. 5. Performance of refined sorbent mixtures for adsorption of $\mathrm{As}, \mathrm{Cd}, \mathrm{Pb}$ and $\mathrm{Zn}$. 

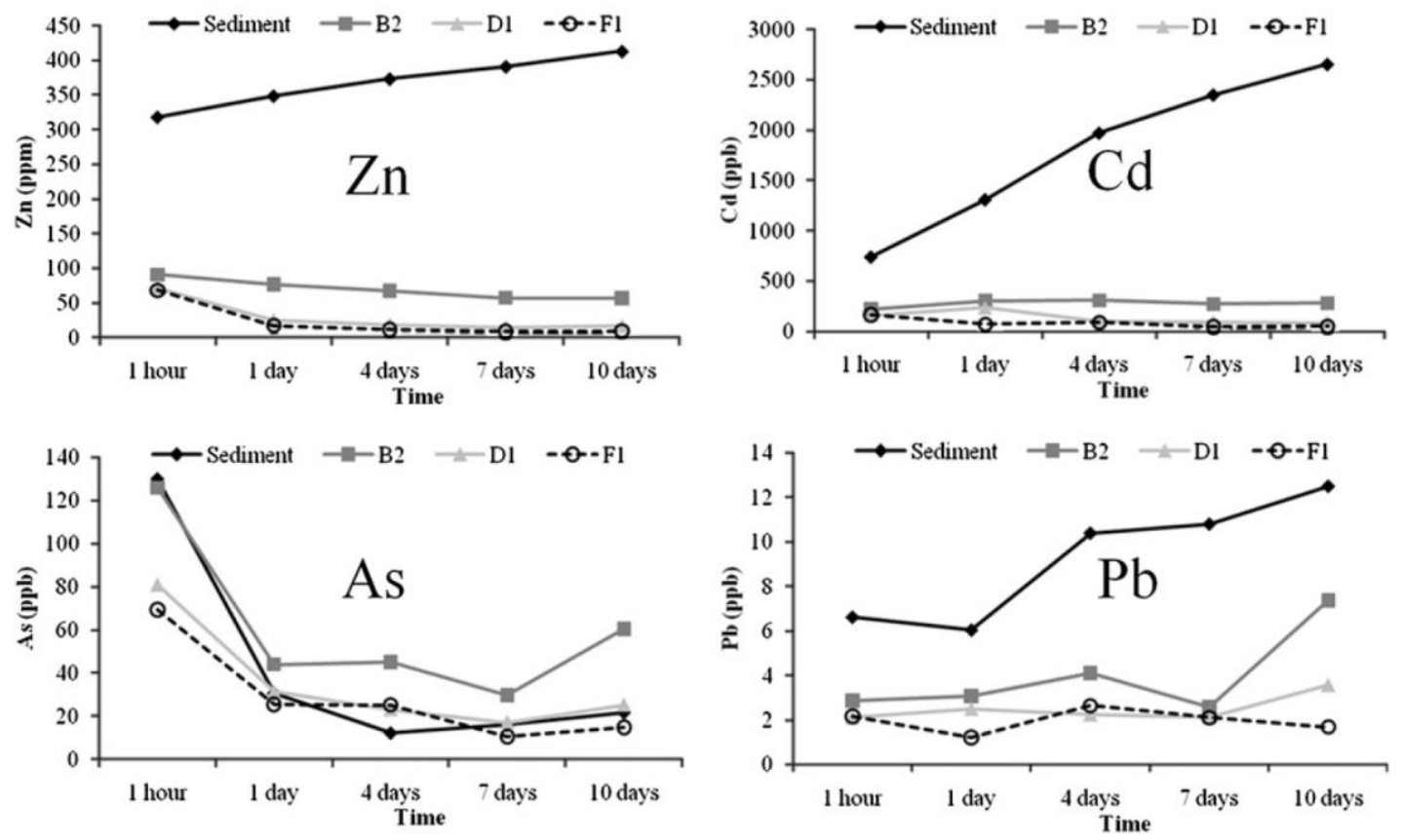

Fig. 6. Stability testing of sediment and sediment with sorbent mixtures. 


\section{List of Tables}

Table 1

Typical analytical techniques for material characterization.

\begin{tabular}{|c|c|c|c|}
\hline Characteristics & Target & Analytical Equipment & Uses \\
\hline $\begin{array}{l}\text { Elemental } \\
\text { Composition }\end{array}$ & $\begin{array}{l}\text { Sediment, } \\
\text { Sorbent }\end{array}$ & $\begin{array}{l}\text { Microwave digestion } \\
\text { Inductively Couple Plasma Mass Spectrometry (ICP-MS) } \\
\text { Atomic absorption spectroscopy (AAS) } \\
\text { X-Ray Fluoresce (XRF) }\end{array}$ & $\begin{array}{l}\text { - Dissolution of solids for aqueous analysis } \\
\text { - Elements present below } 1 \mathrm{wt} \% \\
\text { - Elements present above } 0.1 \mathrm{wt} \% \\
\text { - Elements above } 1 \mathrm{wt} \%\end{array}$ \\
\hline Mineralogy & $\begin{array}{l}\text { Sediment, } \\
\text { Sorbent }\end{array}$ & X-Ray Diffraction (XRD) & $\begin{array}{l}\text { - Crystalline phases of sediment } \\
\text { - Characterization of sorbents }\end{array}$ \\
\hline $\begin{array}{l}\text { Aqueous } \\
\text { Concentration }\end{array}$ & $\begin{array}{l}\text { Surface water, } \\
\text { Porewater, } \\
\text { Filtrates }\end{array}$ & $\begin{array}{l}\text { Inductively Couple Plasma Mass Spectrometry (ICP-MS) } \\
\text { Atomic absorption spectroscopy (AAS) }\end{array}$ & - Solution concentrations \\
\hline
\end{tabular}




\section{Table 2}

Decision Matrix tabulation (hypothetical example).

\begin{tabular}{llllll}
\hline Factor & Criteria & Sorbent 1 & Sorbent 2 & Sorbent 3 & Sorbent $\mathrm{n}$ \\
\hline $\mathrm{pH}$ & $\mathrm{pH}$ suitability & $>5$ & wide & $>6$ & $\ldots$ \\
& $\mathrm{pH}$ effect & 1 & 2 & 0 & $\ldots$ \\
\multirow{2}{*}{ Metal 1 } & Adsorption & 2 & 1 & 1 & $\ldots$ \\
& Precipitation & 0 & 2 & 1 & $\ldots$ \\
\multirow{2}{*}{ Metal 2 } & Adsorption & 1 & -1 & 1 & $\ldots$ \\
& Precipitation & 0 & 1 & 0 & $\ldots$ \\
\multirow{2}{*}{ Metal n } & Adsorption & $\ldots$ & $\ldots$ & $\ldots$ & $\ldots$ \\
& Precipitation & $\ldots$ & $\ldots$ & $\ldots$ & $\ldots$ \\
\hline Overall & Sum & 4 & 5 & 3 & $\ldots$ \\
\hline
\end{tabular}




\section{Table 3}

Sorbent mixture components and contributory levels (hypothetical example)

\begin{tabular}{lll}
\hline Sorbent Mixture & Mixture score & Composition (and estimated sorption contribution level \%) \\
\hline A & 9 & Sorbent 1 $(44 \%)+$ Sorbent 2 $(56 \%)$ \\
B & 12 & Sorbent 1 $(33 \%)+$ Sorbent 2 $(42 \%)+$ Sorbent 3 $(25 \%)$ \\
N & $\ldots$ & $\ldots$ \\
\hline
\end{tabular}




\section{Table 4}

Procedure for determination of sorbent mixture compositions and dosages.

\section{Calculation Procedures}

Determine the Initial Contaminant Concentrations from porewater analysis.

$>$ Determine the Final Equilibrium Concentrations by targeting a percentage removal performance, or referencing regulation limits.

$>$ Use the Sorption Isotherm Fitted Equations (Section 3.2.1) to find the equivalent Sorption Capacities at equilibrium corresponding to the desired target reduction for each heavy metal.

$>$ Combine Contaminant Equilibrium, and Contaminant Supply Totalization values (Section 3.1.3) to determine the total amount of Contaminant Removal needed.

$>$ Determine the Individual Sorbent Dosages (grams sorbent per gram sediment) by the ratio of the Contaminants Removals to the Sorption Capacities. For a multi-element problem, multiple dosages are presented. A selection between the largest dosage value and the dosage value for the most dominant contaminant should be sufficient, as the sum of individual dosages would be an overestimation.

The contributory levels described in Table 3 are used to multiply the dosage of each sorbent by the percentage values. The resulting dosages of each sorbent can be summed to obtain the total mixture dosage (grams sorbent mixture per gram sediment) and can be used to express the mixture composition in weight percentage (wt \%). 


\section{Table 5}

Characterization of contaminated sediment, associate water and contaminant mobility

\begin{tabular}{llllll}
\hline & $\mathrm{pH}$ & $\mathrm{As}$ & $\mathrm{Cd}$ & $\mathrm{Pb}$ & $\mathrm{Zn}$ \\
\hline Sediment $(\mathrm{mg} / \mathrm{kg})$ & - & 8,530 & 20,600 & 1,210 & 42,600 \\
Porewater $(\mu \mathrm{g} / \mathrm{l})$ & 5.2 & 18 & 3,252 & 13 & 272,300 \\
Surface water $(\mu \mathrm{g} / \mathrm{l})$ & 6.1 & 71 & 1,759 & 28 & 64,300 \\
Contaminant Mobility $(\mu \mathrm{g} / \mathrm{l})$ & 5.2 & 5 & 3,574 & 2 & 216,000 \\
Contaminant Supply Totalization $(\mu \mathrm{g} / \mathrm{l})$ & 4.0 & 211 & 10,479 & 30 & 709,000 \\
\hline
\end{tabular}




\section{Table 6}

Reported sorbents performance (maximum capacity) summary

\begin{tabular}{|c|c|c|c|c|}
\hline Sorbent & $\begin{array}{l}\text { As (Min-Max) } \\
\text { (mg/g Sorbent) }\end{array}$ & $\begin{array}{l}\text { Cd (Min-Max) } \\
\text { (mg/g Sorbent) }\end{array}$ & $\begin{array}{l}\mathrm{Pb}(\text { Min-Max }) \\
\text { (mg/g Sorbent) }\end{array}$ & $\begin{array}{l}\text { Zn (Min-Max) } \\
\text { (mg/g Sorbent) }\end{array}$ \\
\hline \multirow[b]{2}{*}{ Goethite } & $0.94-75$ & $0.3-3$ & $1.2-25$ & 0.35 \\
\hline & $\begin{array}{l}\text { Tang et al, 2010, } \\
\text { Lins and Puls, } 2003\end{array}$ & $\begin{array}{l}\text { Balistrieri and Murray, } 1982 \\
\text { Angove et al, } 1999\end{array}$ & $\begin{array}{l}\text { Balistrieri and Murray,1982, } \\
\text { Villalobos and Pérez-Gallegos, } 2008\end{array}$ & Balistrieri and Murray, 1982 \\
\hline \multirow{2}{*}{ HAP } & \multirow[b]{2}{*}{ - } & $0.06-188$ & $0.37-676$ & $3.8-37$ \\
\hline & & $\begin{array}{l}\text { Boisson et al., } 1999 \\
\text { Corami et al., } 2008\end{array}$ & $\begin{array}{l}\text { Boisson et al., } 1999 \\
\text { Smiciklas et al., } 2008 \\
\end{array}$ & $\begin{array}{l}\text { Smiciklas et al., } 2008 \\
\text { Boisson et al., } 1999 \\
\end{array}$ \\
\hline \multirow[b]{2}{*}{ N. Zeolite } & $0.04-36$ & $1.1-13.3$ & $6.2-184$ & $2.0-13.1$ \\
\hline & $\begin{array}{l}\text { Ruggieri et al., } 2008 \\
\text { Chutia et al, } 2009\end{array}$ & $\begin{array}{l}\text { Hamidpour et al. } 2010 \\
\text { Panuccio et al. } 2009\end{array}$ & $\begin{array}{l}\text { Motsa et al. } 2011 \\
\text { Jacobs and Förstner } 1999\end{array}$ & $\begin{array}{l}\text { Sheta et al, } 2003 \\
\text { Perić et al. } 2004\end{array}$ \\
\hline \multirow{2}{*}{$\begin{array}{l}\text { Synthetic } \\
\text { zeolite }\end{array}$} & \multirow[b]{2}{*}{ - } & $4.5-95.5$ & $70.5-524$ & 100 \\
\hline & & Lin et al. 1998 & $\begin{array}{l}\text { Shawabkeh et al. } 2004 \\
\text { Qiu and Zheng } 2009\end{array}$ & Qiu and Zheng 2009 \\
\hline \multirow{2}{*}{ WTRs } & 7.5 & \multirow{2}{*}{-} & \multirow{2}{*}{ - } & \multirow{2}{*}{-} \\
\hline & Sarkar et al. 2007 & & & \\
\hline
\end{tabular}




\section{Table 7}

Zinc sorption capacities determined from isotherm testing and Langmuir fitting.

\begin{tabular}{lccccc}
\hline & Goethite & N. Zeolite & Hap & WTS-1 & WTS-2 \\
\hline Max. capacity, $D_{m}(\mathrm{mg} / \mathrm{g})$ & 4.7 & 3.1 & 117.9 & 14.0 & 23.3 \\
Capacity at $90 \%$ removal, $D_{90 \%}(\mathrm{mg} / \mathrm{g})$ & 3.1 & 2.5 & 91.7 & 9.6 & 14.4 \\
\hline
\end{tabular}




\section{Table 8}

Individual sorbent test observations

\begin{tabular}{|c|c|c|}
\hline Individual Sorbent & Advantages & Disadvantages \\
\hline Goethite & Complete removal of As. & $\begin{array}{l}\text { Low } \mathrm{Zn} \text { removal (max. } 11 \%) \text {, no } \\
\text { effect on } \mathrm{Cd} \text {. }\end{array}$ \\
\hline N. Zeolite & Complete removal of As. & $\begin{array}{l}\text { Inefficient removal of } \mathrm{Zn}(\max \text {. } \\
37 \%) \text { and } \mathrm{Cd}(\max .9 \%) \text {. }\end{array}$ \\
\hline HAP & $\begin{array}{l}\text { Balanced removal of } \mathrm{Zn}(\max .92 \%) \\
\text { and } \mathrm{Cd}(\max .91 \%) .\end{array}$ & $\begin{array}{l}\text { Increased As leaching (up to } \\
107 \mathrm{ppb} \text { ). }\end{array}$ \\
\hline WTS-1 & $\begin{array}{l}\text { High } \mathrm{Zn} \text { removal (max. } 100 \% \text { ), high } \\
\text { efficiency at low dosage. }\end{array}$ & $\begin{array}{l}\text { Significant } \mathrm{pH} \text { increase (up to } 7.8) \text {, } \\
\text { increased As leaching }(91 \mu \mathrm{g} / 1) \text {, } \\
\text { inefficient Cd removal (max. } 51 \%) \text {. }\end{array}$ \\
\hline WTS-2 & $\begin{array}{l}\text { Balanced high removal of } \mathrm{Zn} \text { (max. } \\
97 \%) \text { and } \mathrm{Cd}(\max .95 \%) \text {. }\end{array}$ & $\begin{array}{l}\text { Mild pH increase (up to } 6.3 \text { ) and As } \\
\text { leaching increase (up to } 47 \mu \mathrm{g} / \mathrm{l} \text { ). }\end{array}$ \\
\hline
\end{tabular}




\section{Table 9}

Performance matrix for individual sorbent test.

\begin{tabular}{llccccc}
\hline \multirow{2}{*}{ Factor } & \multicolumn{1}{c}{ Criteria } & Goethite & N. Zeolite & HAP & WTS-1 & WTS-2 \\
\hline \multirow{2}{*}{$\mathrm{pH}$} & $\mathrm{pH}$ & $>5$ & $>6$ & wide & wide & $>5$ \\
& $\begin{array}{l}\text { suitability } \\
\mathrm{pH} \text { effect }\end{array}$ & 0 & 0 & 1 & 2 & 1 \\
\hline \multirow{2}{*}{$\mathrm{As}$} & Adsorption & 2 & 2 & 0 & 0 & 0 \\
& Precipitation & 0 & 0 & -1 & -1 & -1 \\
\hline \multirow{2}{*}{$\mathrm{Cd}$} & Adsorption & -1 & -1 & 2 & 0 & 2 \\
& Precipitation & 0 & 0 & 0 & 2 & 1 \\
\hline \multirow{2}{*}{$\mathrm{Pb}$} & Adsorption & 0 & 0 & 0 & 0 & 0 \\
& Precipitation & 0 & 0 & 0 & -1 & 0 \\
\hline \multirow{2}{*}{$\mathrm{Zn}$} & Adsorption & 1 & 1 & 2 & 0 & 1 \\
& Precipitation & 0 & 0 & 1 & 2 & 1 \\
\hline Overall & & 2 & 2 & 5 & 4 & 5 \\
\hline
\end{tabular}




\section{Table 10}

Sorbent mixtures chosen for application study (percentage values indicate adsorption contribution levels of individual sorbents).

\begin{tabular}{lccl}
\hline Category & Mixture & Score & Composition (and estimated sorption contribution \%) \\
\hline Full & A & 7 & HAP $(71 \%)+$ Goethite $(29 \%)$ \\
Commercial & B & 7 & HAP $(71 \%)+$ Natural Zeolite $(29 \%)$ \\
\hline Partial & C & 11 & HAP $(45 \%)+$ WTS-1 (37\%) + Natural Zeolite $(18 \%)$ \\
Commercial & D & 12 & HAP $(41 \%)+$ WTS-2 (43\%) + Natural Zeolite $(16 \%)$ \\
\hline Full & E & 7 & WTS-2 (71\%) + Goethite (29\%) \\
Substitution & F & 7 & WTS-2 (71\%) + Natural Zeolite $(29 \%)$ \\
\hline
\end{tabular}

Based on adsorption capacities estimated from isotherm performance for $90 \%$ zinc removal (Table 7), the sorption contribution percentages presented in Table 10, the contaminant supply totalization values shown in Table 5, and the calculation procedure detailed in Table 4, the exact composition of each sorption mixture and their respective dosages were determined (Table 11). 


\section{Table 11}

Sorbent mixture compositions (wt \%) and dosages (grams sorbent mixture per gram sediment).

\begin{tabular}{llllllc}
\hline Mixture & Goethite & N. Zeolite & HAP & WTS-1 & WTS-2 & Dosage (g/g) \\
\hline A & $85 \%$ & - & $15 \%$ & - & - & 0.66 \\
B & - & $88 \%$ & $12 \%$ & - & - & 0.85 \\
C & - & $61 \%$ & $8 \%$ & $31 \%$ & - & 0.77 \\
D & - & $63 \%$ & $9 \%$ & - & $28 \%$ & 0.65 \\
E & $65 \%$ & - & & - & $35 \%$ & 0.86 \\
F & - & $71 \%$ & & - & $29 \%$ & 1.02 \\
\hline
\end{tabular}


Table 12

Sorbent mixture refined compositions (grams of sorbent per gram of sediment).

\begin{tabular}{llll}
\hline Mixture & $\begin{array}{l}\text { N. Zeolite } \\
(\mathrm{g} / \mathrm{g})\end{array}$ & $\begin{array}{l}\text { HAP } \\
(\mathrm{g} / \mathrm{g})\end{array}$ & $\begin{array}{l}\text { WTS-2 } \\
(\mathrm{g} / \mathrm{g})\end{array}$ \\
\hline B1 & 0.75 & 0.15 & - \\
$\mathrm{B} 2$ & 0.37 & 0.15 & - \\
$\mathrm{D} 1$ & 0.41 & 0.06 & 0.14 \\
D2 & 0.54 & 0.06 & 0.18 \\
F1 & 0.54 & - & 0.23 \\
F2 & 0.72 & - & 0.30 \\
\hline
\end{tabular}

